\title{
Anemia carencial na infância: um importante problema de saúde pública
}

\author{
Nutritional anemia during childhood: an important public health problem
}

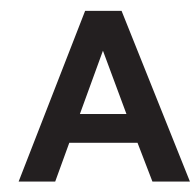

s carências nutricionais constituem problema relevante para a saúde das crianças e dos adolescentes. Globalmente, apesar de atravessarmos um período de transição nutricional, com importante redução na prevalência da desnutrição infantil, a anemia carencial, infelizmente, desponta no contexto atual como uma grande endemia(1).

A anemia é considerada uma preocupação para a saúde populacional quando a freqüência dos valores de hemoglobina abaixo dos pontos de corte referendados para as diversas faixas etárias compromete mais de $5 \%$ dos indivíduos. A sua prevalência entre 5 e 19,9\% caracteriza um problema discreto; de 20 a 39,9\%, um problema moderado; e $40 \%$ ou mais, uma grave situação de Saúde Pública(2).

O Brasil mostra índices crescentes de prevalência de anemia, com níveis que chegam a $70 \%$ em algumas regiões ${ }^{(3)}$. Isto é apenas uma demonstração parcial do problema, uma vez que, ocultos na população, encontram-se até duas vezes mais casos não diagnosticados de deficiência de ferro, considerada hoje a carência nutricional de maior prevalência no mundo(2).

A prevalência de anemia encontrada no estudo de Rocha et al, publicado no presente fascículo da Revista Paulista de Pediatria, foi de $28,7 \%{ }^{(3)}$ - uma das menores quando comparada aos estudos em outras regiões brasileiras ${ }^{(4-6)}-$, mas, ainda assim, representa considerável preocupação para a saúde destas crianças. Entretanto, ainda segundo Rocha et al, a prevalência de anemia foi de $71,4 \%{ }^{(3)}$ em crianças menores de 24 meses, nas creches de Belo Horizonte, Minas Gerais, número que enfatiza o grave comprometimento desta população e revela índices semelhantes aos mais elevados encontrados no Brasil. Tal dado reforça a literatura, a qual indica que os lactentes representam o grupo mais suscetível ao desenvolvimento de anemia. Essa faixa etária concentra fatores de risco, como o rápido ritmo de crescimento e a maior necessidade de ferro, associados à introdução de alimentação complementar, com oferta e/ou aceitação de ferro muitas vezes irregular e desqualificada em conteúdo e biodisponibilidade ${ }^{(7)}$.

Neste contexto, o estudo de Dewey e Brown demonstrou que a utilização de alimentos complementares não fortificados para lactentes nos países em desenvolvimento, apesar de dieta mista, não preenche as necessidades nutricionais para muitos minerais e vitaminas - dentre eles o ferro - nas crianças estudadas ${ }^{(8)}$.

$\mathrm{Na}$ avaliação do estado nutricional, Rocha et al encontraram também valores acima do esperado: $4,2 \%$ para baixa estatura, $5 \%$ para o índice de peso/ estatura, com a maior prevalência para o índice peso/ idade de $5,5 \%{ }^{(3)}$. Isto difere dos demais estudos realizados em creches no Brasil, disponíveis na literatura, em que o deficit estatural foi o indicador antropométrico que demonstrou maior comprometimento ${ }^{(4,6,9,10)}$. No estudo de Rocha et al, apenas as crianças menores de 60 meses anêmicas apresentaram índice altura/idade com diferença significante, quando comparadas às não anêmicas ${ }^{(3)}$. A maioria das evidências encontradas na literatura demonstra alguma relação entre desnutrição crônica e anemia ${ }^{(11,12)}$.

A anemia, devido à carência de ferro, traz importantes repercussões para a saúde da criança, as quais incluem desde uma maior suscetibilidade às infecções, até graus variáveis de comprometimento do crescimento e do desenvolvimento cognitivo e motor ${ }^{(1,2)}$.

Objetivando combater a anemia, o Ministério da Saúde iniciou, na região Nordeste, em 1998, a suplementação semanal de sulfato ferroso oral ${ }^{(13)}$. Contudo, a implementação do programa de suplementação não levou à redução significativa da anemia. Dentre as possíveis razões para esta ineficiência, considera-se, talvez, a falta de aderência à dose e à freqüência recomendadas (muitas vezes relacionadas aos efeitos colaterais), o insuficiente suporte e a falta de monitorização.

Em vários países, a fortificação de alimentos com ferro mostrou-se uma medida bastante eficaz no combate à deficiência de ferro. A fortificação de ali- 
mentos como farinhas, açúcar, cereais, sucos, leite e água, entre outros, mostrou bons resultados na prevenção da anemia carencial. A partir de 2004, foi determinação obrigatória no Brasil a adição de $4,2 \mathrm{mg}$ de ferro (30\% da ingestão diária recomendada - IDR) e $150 \mathrm{mcg}$ de ácido fólico ( $70 \%$ da IDR) para cada $100 \mathrm{~g}$ das farinhas de milho e trigo fabricadas $^{(13)}$. Entretanto, tal medida não contempla a faixa etária de maior risco: o lactente. Além disso, no nosso país, não há vigilância sobre a efetividade de execução desta medida, bem como a monitoração do controle de qualidade.

Como perspectiva para melhorar a efetividade da suplementação de ferro alimentar entre os lactentes, existem alguns estudos promissores com biofortificação, alimentos geneticamente modificados, seleção de sementes e do solo. Outros estudos envolvem a restauração de alimentos, a reposição do ferro perdido durante o processo de industrialização.

É extremamente louvável a iniciativa dos autores de analisar os dados epidemiológicos deste grave problema no município de Belo Horizonte. A fidedignidade dos dados obtidos é fundamental para priorizar os problemas de Saúde Pública da região, para monitorar este tipo de agravo e intervir com o estabelecimento urgente de alternativas e estratégias efetivas de prevenção.

\section{Marileise dos Santos Obelar ${ }^{1}$}

\section{Referências bibliográficas}

1. Kraemer K, Zimmermann M, editors. Nutritional anemia. Basel: Sight and Life Press; 2007.

2. Unicef/UNU/NHO. Iron deficiency anaemia: assessment, prevention and control. A guide for programme managers [report no. 01.3]. Genebra: WHO/NHD; 2001.

3. Rocha DS, Lamounier JA, Capanema FD, Franceschini SC, Norton RC, Costa $A B$ et al. Estado nutricional e anemia em crianças que freqüentam creches em Belo Horizonte. Rev Paul Pediatr 2008;26:6-13

4. Bueno MB, Selem SS, Arêas JA, Fisberg RM. Prevalência e fatores associados à anemia entre crianças atendidas em creches públicas de São Paulo. Rev Bras Epidemiol 2006;9:462-70.

5. Brunken GS, Guimarães LV, Fisberg M. Anemia em crianças menores de 3 anos que freqüentam creches públicas em período integral. J Pediatr (Rio J) 2002;78:50-6.

6. Almeida CA, Ricco RG, Ciampo LA, Souza AM, Pinho AP, Oliveira JE. Fatores associados à anemia por deficiência de ferro em crianças pré-escolares brasileiras. J Pediatr (Rio J) 2004;80:229-34.

7. Osório MM. Fatores determinantes da anemia em crianças. J Pediatr (Rio J) 2002;78:269-78.

8. Dewey KG, Brown KH. Update on technical issues concerning complementary feeding of young children in developing countries and implications for intervention programs. Food Nutr Bull 2003;24:5-28.

9. Silva MV, Ometto AM, Furtuoso CO, Pipitone MA, Sturion GL. Acesso à creche e estado nutricional das crianças brasileiras: diferenças regionais, por faixa etária e classes de renda. Rev Nutr 2000;13:193-9.

10. Fisberg RM, Marchioni DM, Cardoso MR. Estado nutricional e fatores associados ao déficit de crescimento de crianças freqüentadoras de creches públicas do Município de São Paulo, Brasil. Cad Saude Publica 2004;20:812-7.

11. Matta IE, Veiga GV, Baião MR, Santos MM, Luiz RR. Anemia em crianças menores de cinco anos que freqüentam creches públicas do município do Rio de Janeiro, Brasil. Rev Bras Saude Matern Infant 2005;5:349-57.

12. Netto MP, Fonseca MM, Miranda AS, Rocha DS, Silva DG, Franceschini SC Relação entre estado nutricional e anemia ferropriva em crianças do município de Viçosa-MG. Rev Pediatr Ceará 2000;1:570.

13. Brasil - Ministério da Saúde. Fabricantes de farinha terão de adicionar ferro e ácido fólico ao produto. Brasília: Anvisa; Resolução 344/2002.
${ }^{1}$ Mestre em Ciências da Saúde pela Universidade Federal de Santa Catarina (UFSC), professora de Pediatria do curso de Medicina da Universidade do Sul de Santa Catarina, especialista em Pediatria com área de atuação Nutrologia e membro efetivo do Departamento de Nutrologia da Sociedade Brasileira de Pediatria. Florianópolis, SC, Brasil.
Endereço para correspondência

Marileise dos Santos Obelar

Rua Pau de Canela, 1.189 - Campeche

CEP 88063-505 - Florianópolis/SC

E-mail: mari_obelar@yahoo.com.br

Recebido em: 28/1/2008 